\title{
Animal study for the development and validation of new tissue adhesives for the use in otorhinolaryngology
}

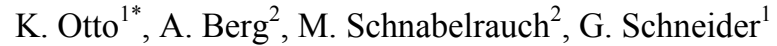 \\ ${ }^{1}$ Friedrich Schiller University Hospital, Department of Otorhinolaryngology, Jena, Germany \\ ${ }^{2}$ INNOVENT e.V. Biomaterials Department, Jena, Germany \\ *Katja.Otto@med.uni-jena.de
}

\begin{abstract}
Introduction The use of adhesives for soft tissue bonding of head and neck represents an interesting alternative to a standard skin suture. In many surgery areas (middle ear, endonasal, pharynx, larynx, trachea) and because of a limited access (endoscope, minimally-invasive), a fixation of tissue by suture is often not possible or restricted. An adhesive bonding with subsequent fixation by scar tissue could be a significant improvement of the surgery results and wound healing. It was the aim of this work to develop a universal, biocompatible and resorbable adhesive for gluing soft tissue. Methods We developed different 2-component adhesives which were tested in vitro and in vivo for their biocompatibility. In vitro, the cytocompatibility of cultured cell lines which were treated with extracts of the different glues was determined using the WST-1 assay. In addition, the new adhesives were examined by fixing defined mucous membrane of the nasal septum in an animal study in rabbits. Results A good cytocompatibility for all new tissue glues tested on cultured cells in vitro was found. The histological examination of the tissue samples showed few remnants of the new adhesives not only after 4 weeks but also after 3 and 6 months. But the surrounding tissue (cartilage, mucous membrane) showed no damage which may be caused by an incompatibility of the adhesives. In contrast, the control group (Histoacryl glue) showed glue residue and tissue damage in form of granulation tissue and cartilage necrosis. Conclusion In summary, new tissue adhesives were developed that show promising results for soft tissue bonding in a moist environment in a first experimental animal study.
\end{abstract}

\section{$1 \quad$ Introduction}

The use of adhesives for soft tissue bonding of head and neck represents an interesting alternative to a standard skin suture. In many surgery areas (middle ear, endonasal, pharynx, larynx, trachea) and because of a limited access (endoscope, minimallyinvasive), a fixation of tissue by suture is often not possible or restricted. An adhesive bonding with subsequent fixation by scar tissue could be a significant improvement of the surgery results and wound healing.

The preconditions for the use of glue in soft tissues are biocompatibility and biodegradation of both the adhesive itself and its degradation products. The glue has to provide a sufficient adhesive force under moist conditions, allowing an immediate functional use of stress-bearing implant beds (pharynx, trachea and esophagus).

Currently, only very few soft tissue adhesives are approved for clinical application.

Fibrin glues consist mainly of plasma proteins, especially fibrinogen and thrombin. They are easy to use, quickly and completely absorbable as well as non-toxic. Their disadvantage is a low adhesive strength and therefore they can not be used in stress-bearing implant beds [1-3].

In contrast, semi-synthetic adhesives like GelatineResorcinol-Formaldehyde (GRF-glue) have a higher adhesive strength. But in contrast to fibrin glue, they usually have insufficient haemostatic effects. In addition to the allergy risks caused by the natural chemical component in these semi-synthetic glues, they contain toxic compounds (formaldehyde or glutaraldehyde) which limit the biocompatibility [1,4-6].

In scientific literature, numerous reports exist about the use of cyanoacrylate glues in soft tissue. These adhesives were developed for gluing skin, and have been proven for this application. To glue soft tissue with cyanoacrylates can be critical due to an excessive, highly exothermic polymerisation reaction in the presence of moisture $[7,8]$. Because of its high adhesive strength, application of this glue in other areas of the human body than skin might be interesting.

The aim of a scientific project funded by BMWi was to develop a universal, biocompatible and resorbable adhesive for gluing soft tissues.

\section{Methods}

The developed adhesive systems consist of two components, an isocyanate-terminated poly(esterurethane) (A/A1) and an aminated poly(oxyethylene) (B). The synthesis of the components A/A1 was performed in a two-step reaction. In the first step, an oligolactone was prepared by ring-opening polymerization of the 
lactone in the presence of a hydroxyl groupcontaining starter followed by reaction of the terminal hydroxyl groups of the formed oligoester with a diisocyanate. Reaction of the component A/A1 with component B results in a cross-linked polyurea.

\subsection{Cell Culture Investigation}

\subsubsection{Preparation of glue extracts}

To test the biocompatibility of both glue systems an extract dilution assay was performed.

Glue samples were transferred into a reaction vessel and polymerised in the presence of cell culture media (DIN ISO 10993: $0.2 \mathrm{~g} / \mathrm{ml}$ extraction volume). The glue-media-mix was incubated at 37 ${ }^{\circ} \mathrm{C}$ over night to harvest the supernatant for subsequent cell culture assays.

\subsubsection{Cell viability test}

All experiments were performed in triplicates and repeated three times. 3T3-mouse fibroblasts were cultured in a nutrient solution (Dulbecco'sModified-Eagle-Medium) supplemented with $10 \%$ fetal calf serum and $0.5 \%$ antibiotics (penicillin/ streptomycin) under standard conditions $\left(37^{\circ} \mathrm{C}, 5\right.$ $\% \mathrm{CO}_{2}$ ). For the experiments, cells were seeded out with a confluence of $30 \%$ in a 96-well plate and incubated for $24 \mathrm{~h}$. Then media was removed and replaced with $200 \mu \mathrm{l}$ per well of glue extract. Cells cultured without glue extract served as negative control. The cells were cultured for further $24 \mathrm{~h}$ or 4 days (with extract changes twice).

Cell viability was assessed using the WST (Water Soluble Tetrazolium)-1 assay (Roche). Viable cells thereby effect an enzymatic conversion of dim red dyed tetrazolium salt in dark red formazan.

Therefore, extracts were removed and replaced with $90 \mu \mathrm{l}$ of phenol red free growth medium and $10 \mu \mathrm{l}$ WST-1 reagents in each well. Plates were incubated for $30 \quad \mathrm{~min}$ at $37{ }^{\circ} \mathrm{C}$ and $5 \quad \% \quad \mathrm{CO}_{2}$. Spectrophotometric analysis was performed on a photometer at a wavelength of $450 \mathrm{~nm}$ (reference: $650 \mathrm{~nm})$.

\subsection{Animal study}

All animal experiments were conducted according to the German Law for Animal Protection and were approved by the local animal care committee. Overall 27 adult female New Zealand White Rabbits were used.

After anesthesia of the animals (Ketamin $40 \mathrm{mg} / 0.4$ $\mathrm{ml}$ and Xylazin $10 \mathrm{mg} / 0.2 \mathrm{ml}$ ), the nasal bridge was shaved and disinfected. For median rhinotomy, the skin was opened by a sagittal incision and the periosteum was displaced. Nasal bones were opened along the sagittal suture using osteotome and divided with a circular saw to open the nasal cavity.

At each side of the nasal septum, two mucosal flaps $(5 \times 5 \mathrm{~mm})$ were released from the cartilage. The glue sample was placed at the exposed nasal septum cartilage areas using micro-suction tubes of defined diameters $(2.0 \mathrm{~mm}, 1.4 \mathrm{~mm}, 1.0 \mathrm{~mm})$. Subsequently, mucosal flaps were put back in position. As control, one dissected mucosal flap was attached to the nasal septum without using glue. The nasal bones were replaced and fixed with sutures. Then, a skin suture with absorbable suture material was made, followed by spray dressing for optimal wound closure. After 4 weeks, 3 months and 6 months animals were sacrificed with $3 \mathrm{ml}$ Narcoren $(160 \mathrm{mg} / \mathrm{ml})$ and nasal septum was removed to fix them in $5 \%$ formaldehyde.

\subsection{Cutting-grinding technique}

The cutting-grinding technique for histological preparation was used to investigate the tissue samples. In brief, tissue samples were fixed in $5 \%$ formaldehyde for 7 days and then dehydrated in an ascending series of ethanol $(50 \%, 70 \%, 80 \%, 96 \%$, $2 \times 100 \%$, each 2 days). Subsequently, tissue samples were infiltrated with a mixture of ethanol and Technovit 7200 (1:1) for 2 days and pure Technovit 7200 for 3 days. In a next step, tissue samples were embedded in Technovit 7200 using the EXAKT photo-polymerisation method. To get serial sections, specimens were sawed to $200 \mu \mathrm{m}$ thick slices by an EXAKT diamond band saw. Using an EXAKT micro-grinding system and wet abrasive papers of different grain sizes $(320,500$, 800,1000 , and 1200), slices were grounded automatically to a thickness of $50 \mu \mathrm{m}$. The final thin-section was prepared by polishing (with polishing paper 4000) to a thickness of $15 \mu \mathrm{m}$. The finished thin-sections were stained using a modified Masson-Goldner-method or HE staining.

\section{$3 \quad$ Results}

\subsection{Cell Culture Investigations}

For studying cytotoxicity in vitro an extract dilution assay was chosen.

3T3-mouse fibroblasts were incubated with extracts of either new glues or Histoacryl for $24 \mathrm{~h}$ or 4 days to access the viability by the WST-1 assay.

Adhesive 1 shows a viability of $83 \%$ after $24 \mathrm{~h}$ (figure 1). The viability changes after 4 days barely (84\%).

Adhesive 2 shows a viability of $98 \%$ after $24 \mathrm{~h}$, and after 4 days a viability of $120 \%$. 
In comparison, Histoacryl as a control shows a viability of $47 \%$ after $24 \mathrm{~h}$ and after 4 days only $30 \%$.

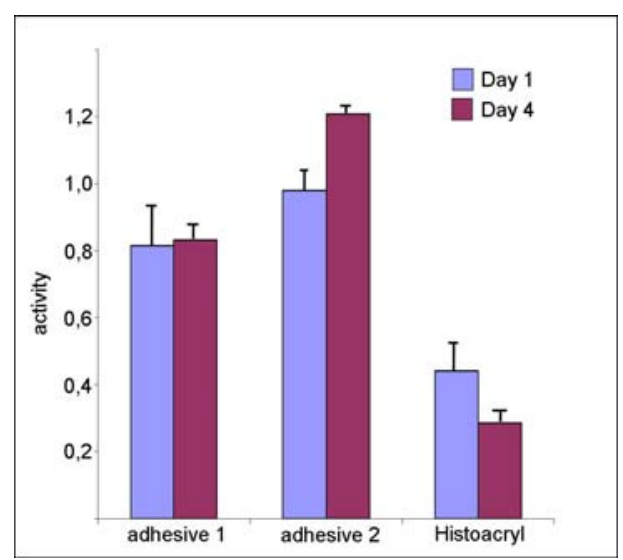

Figure 1: The viability of $3 \mathrm{~T} 3$ mouse fibroblasts is shown in contact with different glues.

\subsection{Animal Study}

The behavior of all animals was unremarkable postoperatively (normal feeding behavior, none died untimely).

After the implantation intervals all animals were sacrificed to harvest tissue samples for a histological assessment.

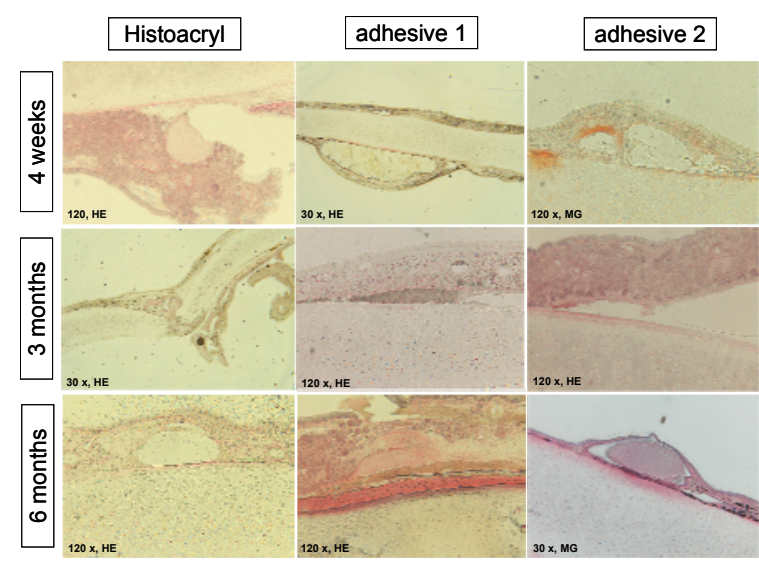

Figure 2: Thin sections of the nasal septum after histological preparation stained either with modified Masson-Goldner method or HE staining.

In all tissue samples of all three points of time (4 weeks, 3 and 6 month) glue remains were still present (figure 2). The adhesive residues were presented well tolerated in the tissue surrounded by mucosa. Granulocytes or tissue damage could not be observed at both new adhesives.

In contrast, the control samples glued with Histoacryl showed inflammatory changes up to cartilage necrosis. Compared with a normal nasal septum numerous foreign body giant cells and macrophages occurred at the places where Histoacryl was applied.

\section{Discussion}

\subsection{Cell Culture Investigations}

In the literature mainly two procedures are described to test cytotoxicity of cured medical adhesives in vitro.

On one side, a test procedure is reported at which cells have direct contact to the glue (direct contact assay) $[9,10]$. On the other hand, it is possible to extract the glue and treat cell lines with the extraction media (extract dilution assay) [11-14]. With both test setups it is possible to investigate cell morphology and cell viability as well as cell proliferation.

In routine investigations cytotoxicity of both new glues were determined by an extraction test. The advantage of this setup is that the cell monolayer can not be mechanically damaged by adding extracts.

The results have shown a good cytocompatibility of both newly developed adhesives in contrast to the cyanoacrylate glue Histoacryl. The cells have grown well in contact with glue extract from the new adhesives showing normal morphology.

Cell culture investigations can provide a first hint for biocompatibility of biomaterials on certain cell types. However, cell cultures usually are static systems, in which sterile pure culture of cells does not reflect the natural (in situ) situation, because the nutrient medium and the attachment substrate are artificial. Therefore, a first in vivo study has been conducted to confirm the promising in vitro results and receive more detailed information on the biocompatibility of the new adhesives.

\subsection{Animal Study}

In the in vivo investigations on rabbits the new adhesives were tested in a moderate bleeding area. After 4 weeks and also after 3 and 6 months both glues were still visible in the histological findings. It is supposed that blood circulation in the glued area and therefore transportation of degradation products influence absorption. Another parameter which influences biocompatibility and also biodegradation of tissue glue is the applied amount of glue. In the experiments micro-suction tubes to apply only small amounts of glue were used. This improvised application does not replace an application system with adjustable dosing.

Especially when mucosa has to be glued, optimal polymerization behaviour of the adhesive with high conversion rates under the conditions of a moist 
environment and a good substrate adhesion and bonding strength are required. The findings of the present study show that the application of both new glues is easy and safe. A well-performed gluing of mucosa to nasal cartilage was possible using very small amounts of glue. The dosages of the new adhesives can readily be adjusted due to the highly viscous consistency of the adhesives. Both glues crosslink slowly enough even under moist conditions making it conveniently possible to fix the glued samples.

\section{Conclusion}

Here, new adhesives for gluing soft tissue in a moist environment are presented. First results of in vitro and in vivo studies showed good biocompatibility.

Further experiments will investigate physical and chemical properties.

\section{Acknowledgements}

This work was supported by the BMWi

(grant no.: KF 2071801SB8).

\section{References}

$1 \quad$ Heiß C, Schnettler R (2005)

Bioresorbierbare Knochenklebstoffe. Unfallchirurg 108:348-355

2 Panis R, Scheele J (1981) Risk of hepatitis in fibrin adhesion. Laryngol Rhinol Otol 60:367-

368

3 Petersen B, Barkun A, Carpenter S, Chotiprasidhi P, Chuttani R, Silverman W, Hussain N, Liu J, Taitelbaum G, Ginsberg, GG (2004)

Tissue adhesives and fibrin glues. Gastrointest Endosc 60:327-333

4 Chao HH, Torchiana DF (2003) BioGlue: Albumin/Glutaraldehyde Sealant in Cardiac Surgery. JCS 18:500-503

5 Costa HJ, Pereira CS, Costa MP, Fabri FS, Lancellotti CL, Dolci JE (2006) Comparison of butyl-2-cyanoacrylate, gelatin-resorcinformaldehyde (GRF) compound and suture in stabilization of cartilage grafts in rabbits. Braz $\mathrm{J}$ Otorhinolaryngol 72:61-71

6 Friedman M, Schalch P (2008) Middle

Turbinate Medialization With Bovine Serum

Albumin Tissue Adhesive (BioGlue).

Laryngoscope 118:335-338

7 Bernard L, Doyle J, Friedlander SF, Eichenfield LF, Gibbs NF, Cunningham BB (2001) A Prospective Comparison of Octyl Cyanoacrylate Tissue Adhesive (Dermabond) and Suture for the
Closure of Excisional Wounds in Children and Adolescents. Arch Dermatol 137:1177-1180 8 Leggat PA, Smith DR, Kedjarune U (2007) Surgical applications of cyanoacrylate adhesives: a review of toxicity. ANZ J Surg 77:209-213

9 Ciapetti G, Cenni E, Sudanese A, Marraro D, Toni A, Pizzoferrato A (1994) Cytotoxicity testing of cyanoacrylates using direct contact assay on cell cultures. Biomaterials 15:63-67

10 Wilkinson JN, Chikhani M, Mortimer K, Gill SJ (2008) The antimicrobial effect of Histoacryl skin adhesive. Anaesthesia 63:13721386

11 Kaplan M, Baysal K (2005) In vitro toxicity test of ethyl 2-cyanoacrylate, a tissue adhesive used in cardiovascular surgery, by fibroblast cell culture method. Heart Surg Forum 8:E169-172

12 Ciapetti G, Stea S, Cenni E, Sudanese A, Marraro D, Toni A, Pizzoferrato A (1994) Toxicity of cyanoacrylates in vitro using extract dilution assay on cell cultures. Biomaterials 15:92-96 13 Montanaro L, Cenni E, Ciapetti G, Savioli F, Filippini F, Barsanti LA (2001) Cytotoxicity, blood compatibility and antimicrobial activity of two cyanoacrylate glues for surgical use.

Biomaterials 22:59-66

14 Thumwanit V (1999) Cytotoxicity of polymerized commercial cyanoacrylate adhesive on cultured human oral fibroblasts. Aust Dent J 44:248-252 